\title{
Harmonic Analysis of Multiterminal DC System With Implementation of DC Transformer
}

\author{
Premalatha. $\mathrm{V}^{1}$, Ilampoornan.M.K ${ }^{2}$ \\ ${ }^{I}$ (Student, M.E ( Power Electronics and Drives), Loyola Institute of Technology/Anna University, India) \\ ${ }_{2}^{2}$ (Professor, Electrical and Electronics Engineering, Loyola Institute of Technology/Anna University, India)
}

\begin{abstract}
The successful working of a two terminal HVDC has led to the development of the multiterminal DC network. This study describes the Principle of developing DC transmission grid based on the high power $D C / D C$ converters with power source available from the renewable sources such as wind, solar and fuel cells etc. The DC/DC converter is capable of achieving very high step up gain with high power level transfer and does not utilize the iron core transformers. The Active filter based on the Instantaneous reactive power theory is implemented on the AC source side of the Renewable sources The efficiency of shunt Active filter is demonstrated using the simulation. It is concluded that DC transmission grid could be developed by DC/DC converters with Active filters successfully implemented to reduce the Harmonics and hence the efficiency of system is increased.
\end{abstract}

Keywords: Active filters, DC/DC converters, Harmonics, HVDC

\section{INTRODUCTION}

High voltage direct transmission has been used for many years. The rapid development of HVDC (High Voltage DC) transmission technologies is also driving demand for DC-DC converters. The recently developed HVDC light (HVDC with Voltage Source Converters) has already been implemented and found to be suitable solution for integration of renewable power sources. In recent days plenty of available renewable sources such as wind ,photo voltaic and fuel cells that would be ideally connected to DC grids are particularly attractive with off shore system. A suitable MW size DC-DC converter would enable linking to HVDC lines and it would aid in development of multi-terminal HVDC [1].

The schematic diagram of simple multi terminal DC network is shown in Fig 1.The renewable sources is converted into DC and stepped up from $5 \mathrm{kV}$ to $100 \mathrm{kV}$ using the DC/DC transformer. The stepped up DC voltage is linked to the HVDC link to form a multi terminal network.

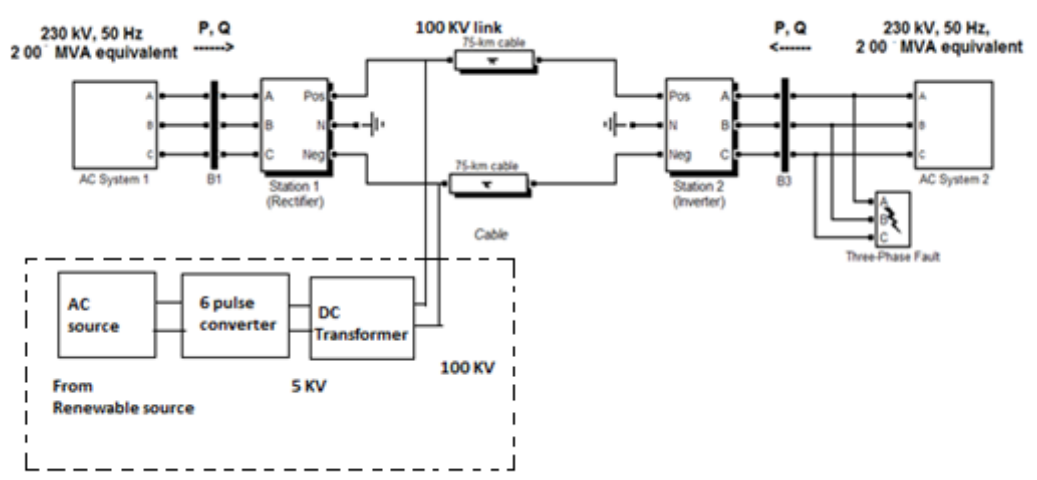

Fig 1 Schematic of multi-terminal network using DC/DC transformer To form the Multi-terminal network the following components are used

1. Simulation of six pulse converter with Active filter implemented on the AC side ( Equivalent Renewable source)

2. DC/DC Transformer (steps up the DC voltage of required rating to HVDC system)

3. Simulation of HVDC system

\section{Simulation Of Six Pulse Converter With Shunt Active Filter}

The renewable source obtained from the various sources such as wind, hydro and fuel cell is represented as 3 phase source is converted into the DC sources with six pulse converter. The current harmonics as measured from the AC and the Active filters is used for Mitigating the harmonics [2]. 
The six pulse converter is implemented to convert the available renewable sources. The Active filter is implemented on the AC side. The order of harmonics generated on the AC side is given by $h=n p \pm 1$ i.e is 5 , $7,11,13 \ldots$...etc where $\mathrm{p}=$ pulse number, $\mathrm{n}=$ integer, $\mathrm{h}=$ order of harmonics.

Active filter is implemented on the $\mathrm{AC}$ side of the six pulse converter using the instantaneous reactive power theory. The active filter is simulated and implementation is done on AC side of the converter as shown in Fig 2

The instantaneous voltages and current are represented as the instantaneous space vectors on the a-b-c coordinate system with the vectors a-b-c fixed on the same plane displaced to each other by 120 degree. Transformation of these space vectors in to $\alpha-\beta$ orthogonal co-ordinate system using concept of instantaneous reactive power theory introduced by Akagi et al. The $\alpha-\beta$ components of voltage and current are used for calculation of Instantaneous reactive power .

The schematic representation of Active filter is represented in Fig.2

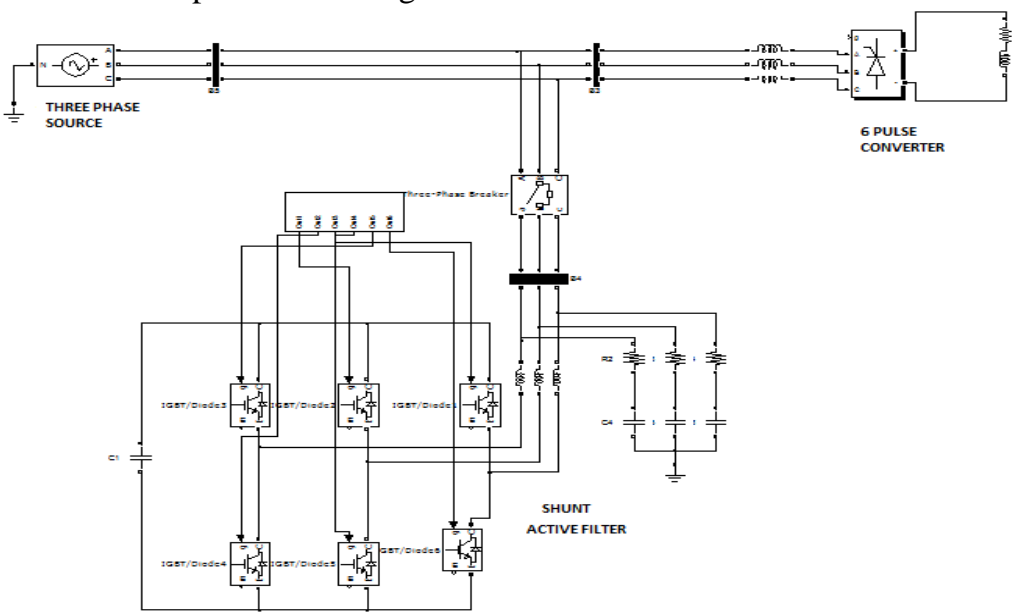

Fig. 2 Simulation of shunt active filter on AC sides of six pulse converter

Let $e_{a}, e_{b}$ and $e_{c}$ be the phase voltage obtained from the source and let $i_{P a}, i_{P b}$ and $i_{P c}$ be the load current. The transformation of phase voltages and load currents into $\alpha-\beta$ orthogonal coordinate is obtained using the matrix equation defined shown in Appendix I.

\section{REFERENCE CURRENT GENERATION}

For harmonic compensation the reference current is generated for the Shunt Active filter. The methods for deriving the reference current of respective phases are discussed in this section. The reference current generation is done based on requirement .Let $i_{c \alpha}, i_{c \beta}$ be the $\alpha-\beta$ components of the compensator current . $e_{\alpha}, e_{\beta}$ be the compensator voltage generated from the shunt Active filter.

In shunt active filter in order to compensate for harmonics $p_{\text {losc }}$ component is considered which is derived from the equation in Appendix I. The reference current generated by the shunt active filter is given below.

$$
\begin{aligned}
i_{r e f a} * & =\sqrt{\frac{2}{3}}\left(\frac{1}{e_{\alpha^{2}}+e_{\beta^{2}}}\right)\left(\left(p^{*}+p_{a v}\right) e_{\alpha}-e_{\beta}\right) \\
i_{r e f b} * & =\sqrt{\frac{2}{3}}\left(\frac{1}{e_{\alpha^{2}}+e_{\beta^{2}}}\right)\left(\left(\frac{\sqrt{3} e_{\beta}-e_{\alpha}}{2}\right)\left(p^{*}+p_{a v}\right)+\left(\frac{\sqrt{3} e_{\alpha}+e_{\beta}}{2}\right)\right) \\
i_{r e f c} * & =\sqrt{\frac{2}{3}}\left(\frac{1}{e_{\alpha^{2}}+e_{\beta^{2}}}\right)\left(-\left(\frac{\sqrt{3} e_{\beta}+e_{\alpha}}{2}\right)\left(p^{*}+p_{a v}\right)+\left(\frac{e_{\beta}-\sqrt{3} e_{\alpha}}{2}\right)\right)
\end{aligned}
$$

Where $\mathrm{p}_{\mathrm{av}}$ is the instantaneous real power corresponding to the loss of the active power filter and $p^{*}$ is given by

$$
p^{*}=-\widetilde{p_{L}}
$$

From the equations the control pulse is generated using triangular carrier signals. This control scheme for the VSC is shown in Fig 3 


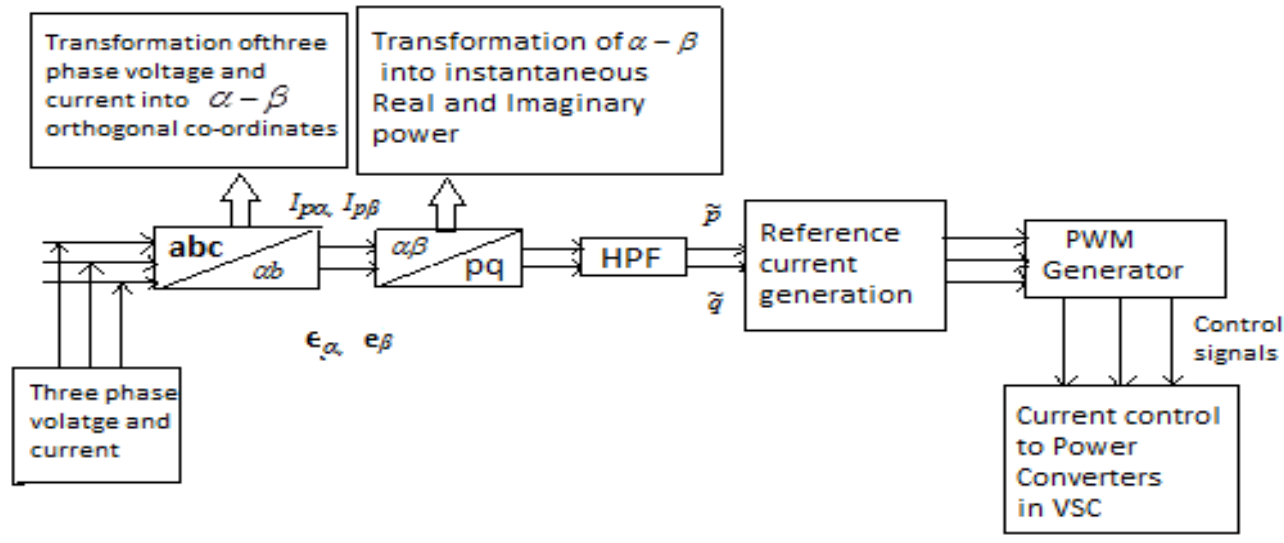

Fig.3 Control strategy for Active filter

\section{Step up DC/DC converter.}

The DC/DC converter is capable of achieving very high step up gain in the order of MW power level transfers. It consists of two bridge circuits with one fully controlled converter and other uncontrolled converter placed around the LC circuit. The advantage of the topology is simplicity and soft switching operations. Further iron core transformers are not used hence the problems of saturation etc related to the transformers does not arise. The step up operation is done by means of resonant converter [4] is shown in Fig 4.1.

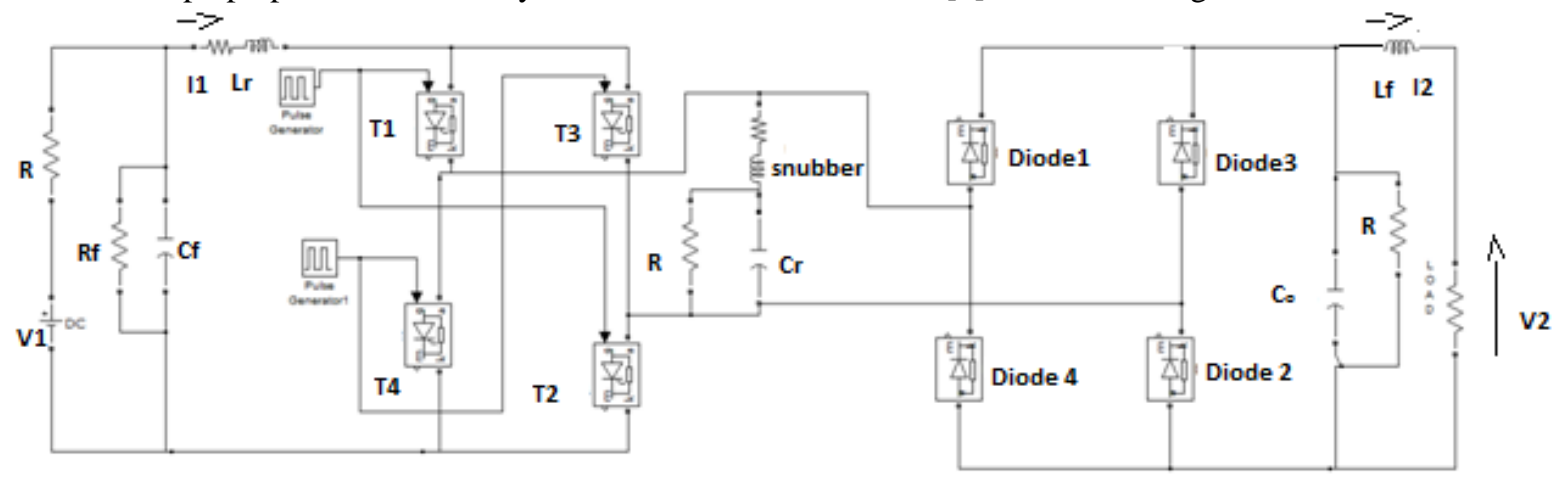

Fig 4.1 Simulation circuit of 5/100 kV step up dc/dc converter

The resonant inductor $\mathrm{Lr}$ resonates with capacitor $\mathrm{Cr}$ for obtaining the required level of voltage. The value of $\mathrm{Cr}$ can be determined from the equation

where

$$
c_{r}=\frac{I_{2}\left(V_{2}-V_{1}\right)}{2 f_{s} V_{1} V_{2}}
$$

$f s=$ Switching frequency, where other variables are defined in Fig 4.1

The step up operation by the resonant converter is done to step up the $5 \mathrm{kV}$ to $100 \mathrm{kV}$. The output voltage across the capacitor $\mathrm{Cr}$ and load is shown in the Fig 4.2.

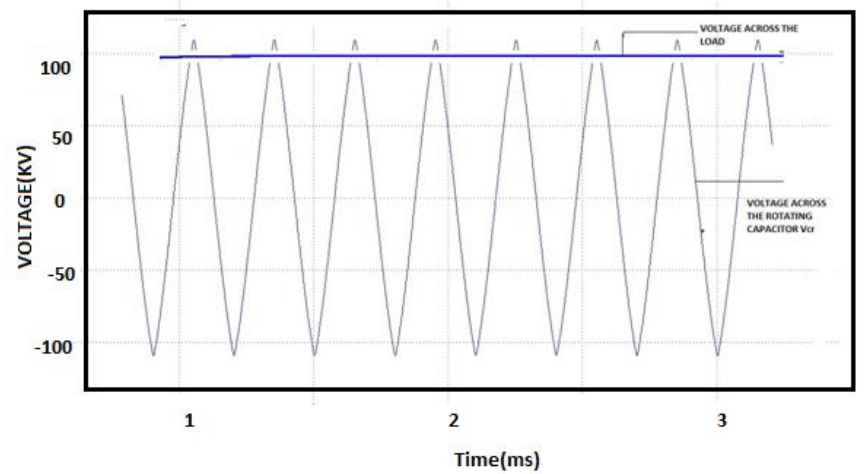

Fig 4.2 Voltage across the rotating capacitor and load 
The output of the resonant converter is linked with the main HVDC transmission line of rating $100 \mathrm{kV}$.

\section{Simulation of main HVDC Transmission system}

The VSC based HVDC system is preferred as it requires inductor and the reactive power supply is not required as the converter can operate in any quadrant. On the DC side of the converter the capacitor act as a energy storing device as well as filter with no extra cost for filtering. The main VSC based HVDC transmission system is shown in Fig 5.1.

The VSC can be considered as the combination of the current sources converter and the SVC(static VAR compensator) in parallel, with an advantage of flexibility in controlling the commutation. The operation of the VSC is based on the operation of the controlled switches such as GTO,IGBT.The nearly sinusoidal output with control in power factor can be obtained due to the commutation which can occur for many times a cycle. The operation of the switches at the high frequency does not affect the shape of the sinusoidal waveform even for multiple firing in a cycle. To control the switches in the converters pulse width modulation(PWM) technique is used. The DC voltage across the load is compared with the reference value $\mathrm{V}_{\text {ref }}$ used to generate the error signals which controls the PWM controller. when the DC current is positive the converter acts as a rectifier. To make VSC as inverter the DC current should be negative. The source capacitor of VSC is charged from the DC source and the system will modify the firing angle to act in inverter mode[5]. The inner decoupled current control and the outer active and the reactive power control is done in VSC. The schematic of VSC control system is shown in Fig 5.2.

The simulation of the HVDC is studied from [6] - [8]

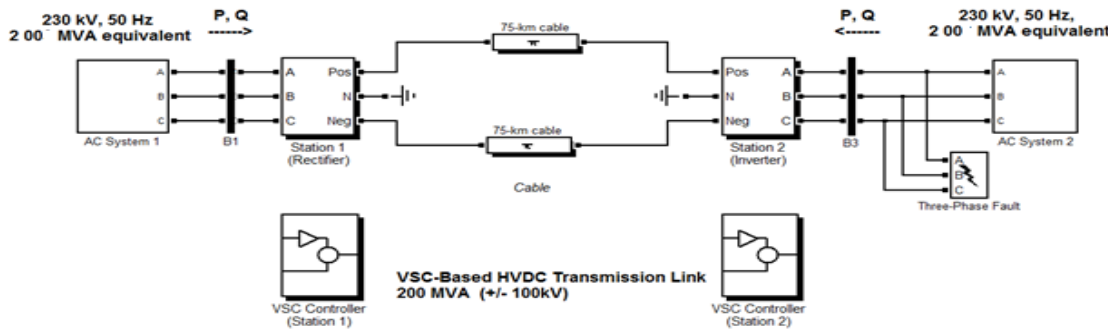

Fig 5.1 VSC-HVDC Transmission System Model

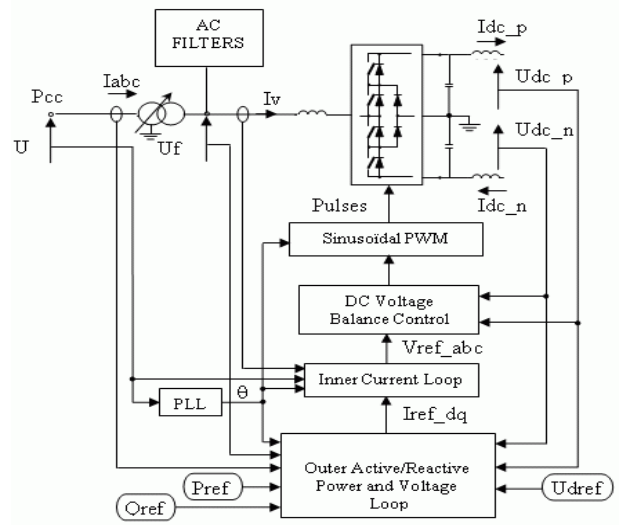

Fig 5.2 VSC control system

VI. Synchronization of renewable source with HVDC transmission line.

The DC transformer is used for connecting the renewable source with the main HVDC transmission line. The impact of synchronization can be observed at various nodes.

The effect of inclusion is also observed in terms of harmonics before and after implementation of Active filter on the AC side of the renewable source.

Table 1 shows the magnitude of current harmonics before the implementation of shunt Active filter.

Table 2 shows the magnitude of current harmonics after the implementation of shunt Active filter. The reduction in the THD level is obvious from the Table $1 \& 2$.

$\%$ THD measured before implementation of Active filter on the six pulse converter near AC source side

$$
=28.54 \%
$$

$\%$ THD measured after implementation of Active filter on the six pulse converter near AC source side

$$
=0.84 \%
$$




$$
\begin{aligned}
\% \text { Reduction of THD level } & =\frac{(28.54-0.84)}{28.54} * 100 \\
& =97.04 \%
\end{aligned}
$$

\section{Ripple factor analysis of HVDC link}

Definition of Ripple factor

The direct voltage is defined by its arithmetic mean value $\mathrm{V}_{\mathrm{d}}$ and expressed as

$$
v_{d}=\frac{1}{T} \int_{0}^{T} v(t) d t
$$

Ripple is the deviation from the mean voltage value periodically [9].

Magnitude of ripple voltage

$$
\delta V=\frac{1}{2}\left(V_{\text {max }}-V_{\text {min }}\right)
$$

Ripple factor is defined as the ratio of ripple magnitude to the mean value $V_{d}$

$$
\text { Ripple factor }=\delta V / V_{d}
$$

As per the standard IEEE- 4,1978, the ripple factor should be $<3 \%$.

Ripple factor observed from the simulations before connection of renewable source with HVDC link is $2 \%$. After the synchronization the ripple factor is increased to $2.8 \%$.This increase in ripple is reflected on the $\mathrm{AC}$ side of both the converter and inverter of main HVDC system, resulting in further increase of THD. It is observed to be well within the IEEE standard of 3\%. The harmonic analysis of HVDC link in station 1(rectifier) and station 2(inverter) after the synchronisation of renewable source with the HVDC system is shown in Table 3 and 4.

VIII. Tables

Table 1: Harmonic analysis on AC source side of 6 pulse converter before implementation of Shunt active filter

\begin{tabular}{|c|c|}
\hline Order of harmonics & Magnitude of Harmonics(A) \\
\hline 5 & 9.52 \\
\hline 7 & 4.72 \\
\hline 11 & 2.36 \\
\hline 13 & 1.12 \\
\hline
\end{tabular}

Table 2: Harmonic analysis on the source side of six pulse converter after implementation of shunt Active filter

\begin{tabular}{|c|c|}
\hline Order of harmonics & Magnitude of Harmonics(A) \\
\hline 5 & 1.2 \\
\hline 7 & 1.1 \\
\hline 11 & 0.84 \\
\hline 13 & 0.4 \\
\hline
\end{tabular}

Table 3 : Harmonic analysis in HVDC link in Station 1(near Rectifier) after the Implementation of Active filter.

\begin{tabular}{|c|c|}
\hline Order of harmonics( THD $\mathbf{4 . 5 1} \%)$ & Magnitude of Harmonics(A) \\
\hline 5 & 7.42 \\
\hline 7 & 5.1 \\
\hline 11 & 0.67 \\
\hline 13 & 0.88 \\
\hline
\end{tabular}

Table 4: Harmonic analysis in HVDC link in Station 2(near Inverter) after the Implementation of Active filter.

\begin{tabular}{|c|c|}
\hline Order of harmonics $(\mathbf{T H D}=\mathbf{4 . 4 7} \%)$ & Magnitude of Harmonics(A) \\
\hline 5 & 7.52 \\
\hline 7 & 5.28 \\
\hline 11 & 5.17 \\
\hline 13 & 3.67 \\
\hline
\end{tabular}

\section{Conclusion}

The Multiterminal HVDC network is formed using the DC/DC transformer with the implementation of Active filter on the AC side of the renewable sources. The Active filter is efficient in the reduction of the current harmonics on the renewable source side. The DC transformer contributes ripples in HVDC link results in AC harmonics and increased THD level in HVDC. Hence the effective place to implement the Active filter is the source side of the main HVDC station. Further work can be done in Active filter implementation on the HVDC station. 


\section{References}

[1] D.Jovic,Boon Teck Ooi,'Developing DC Transmission Network using DC Transformer" IEEE Transaction on power delivery ,Vol.25,No.4,October 2010.

[2] Chan-ki-kim, HVDC transmission power conversion applications in power systems( John wiley \& sons(Asia) pte Ltd, 2009).

[3] Hirofumi Akagi, Akira Nabar and Satosi Atoh"control strategy of active power filters using multiple voltage- source PWM converters" proc in IEEE transactions on Industry Application, Vol. IA-22.NO.3, May/June 1986.

[4] D.Jovcic "Step up DC-DC converter for MW-size applications" IET Power Electronics, PEL-2008-0101, April 2008.

[5] Vijay k sood ,HVDC and FACTS controller Application of static converters in powerv system @ 2004 Kluwer Academic publishers Boston

[6] Schettler F., Huang H., and Christl N. "HVDC transmission systems using voltage source converters - design and applications," IEEE Power Engineering Society Summer Meeting, July 2000

[7] Lindberg, Anders "PWM and control of two and three level high power voltage source converters," Licentiate thesis, ISSN1100-1615, TRITA-EHE 9501, The Royal Institute of Technology, Sweden, 1995.

[8] Sadaba, Alonso, O., P. Sanchis Gurpide, J. Lopez Tanerna, I. Munoz Morales, L. Marroyo Palomo, "Voltage Harmonics Generated by 3-Level Converters Using PWM Natural Sampling," Power Electronics Specialist Conference, 2001, IEEE 32nd Annual, 17-21 June 2001, vol. 3, pp. 1561-1565.

[9] Dieter Kind and Kurt Feser, High voltage test technique (Newens, $2^{\text {nd }}$ revised and enlarged edition).

\section{APPENDIX I}

For transforming voltage in abc phase to $\alpha-\beta$ shown is

$$
\left[\begin{array}{l}
e_{\alpha} \\
e_{\beta}
\end{array}\right]=\sqrt{\frac{2}{3}}\left[\begin{array}{ccc}
1 & -1 / 2 & -1 / 2 \\
0 & \sqrt{3} / 2 & -\sqrt{3} / 2
\end{array}\right]\left[\begin{array}{l}
e_{a} \\
e_{b} \\
e_{c}
\end{array}\right]
$$

For current the transformation from abc phase to $\alpha-\beta$ is

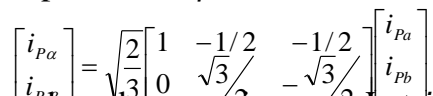

The reference current generation is done $i_{p}$ ased on requirement. L L e tet $j_{c \alpha}, i_{c \beta}$ be the $\alpha-\beta$ components of the compensator current and $e_{\alpha}, e_{\beta}$ be the $\alpha-\beta$ components of the source voltage

$$
\left[\begin{array}{l}
i_{c \alpha} \\
i_{c \beta}
\end{array}\right]=\frac{1}{e_{a}^{2}+e_{\beta}^{2}}\left[\begin{array}{cc}
e_{\alpha} & -e_{\beta} \\
e_{\beta} & e_{\alpha}
\end{array}\right]\left[\begin{array}{c}
p_{\text {losc }} \\
q_{1}
\end{array}\right]
$$

For harmonic compensation the equation (3) can be modified as

$$
\left[\begin{array}{l}
i_{c \alpha} \\
i_{c \beta}
\end{array}\right]=\frac{1}{e_{a}^{2}+e_{\beta}^{2}}\left[\begin{array}{cc}
e_{\alpha} & -e_{\beta} \\
e_{\beta} & e_{\alpha}
\end{array}\right]\left[\begin{array}{c}
p_{\text {losc }} \\
0
\end{array}\right]
$$

